\title{
Occurrence, Distribution, and Polymerase Chain Reaction-Based Detection of Resistance to Sterol Demethylation Inhibitor Fungicides in Populations of Blumeriella jaapii in Michigan
}

\author{
Tyre J. Proffer, Raffaele Berardi, Zhonghua Ma, James E. Nugent, \\ Gail R. Ehret, Patricia S. McManus, Alan L. Jones, and George W. Sundin
}

First author: Department of Biological Sciences, Kent State University, Salem, OH 44460; first, second, third, fifth, seventh, and eighth authors: Department of Plant Pathology, Michigan State University, East Lansing 48824; second author: Dipartimento di Protezione e Valorizzazione Agroalimentare, University of Bologna, Bologna, Italy; fourth author: Northwest Michigan Horticultural Research Station, Traverse City, MI 49684; and sixth author: Department of Plant Pathology, University of Wisconsin, Madison 53706. Current address of third author: Biotechnology Institute, Zhejiang University, Hanghzou 310029, P.R. China.

Accepted for publication 8 February 2006.

\begin{abstract}
Proffer, T. J., Berardi, R., Ma, Z., Nugent, J. E., Ehret, G. R., McManus, P. S., Jones, A. L., and Sundin, G. W. 2006. Occurrence, distribution, and polymerase chain reaction-based detection of resistance to sterol demethylation inhibitor fungicides in populations of Blumeriella jaapii in Michigan. Phytopathology 96:709-717.

The intensive use of site-specific fungicides in agricultural production provides a potent selective mechanism for increasing the frequency of fungicide-resistant isolates in pathogen populations. Practical resistance occurs when the frequency and levels of resistance are great enough to limit the effectiveness of disease control in the field. Cherry leaf spot (CLS), caused by the fungus Blumeriella jaapii, is a major disease of cherry trees in the Great Lakes region. The site-specific sterol demethylation inhibitor fungicides (DMIs) have been used extensively in the region. In 2002, CLS control failed in a Michigan orchard that had used the DMI fenbuconazole exclusively for 8 years. That control failure and our observations from around the state suggested that practical resistance had developed in B. jaapii. Field trial data covering 1989 to 2005 for the DMIs fenbuconazole and tebuconazole supported observations of reduced efficacy of DMIs for controlling CLS. To verify the occurrence of fungicideresistant B. jaapii, monoconidial isolates were collected in two surveys

and tested using a fungicide-amended medium. In one survey, 137 isolates from sites with different DMI histories (no known history, mixed or alternated with other fungicides, and exclusive use) were tested against 12 concentrations of fenbuconazole, tebuconazole, myclobutanil, and fenarimol. Isolates from sites with no prior DMI use were DMI sensitive $\left(\mathrm{DMI}^{\mathrm{S}}=\right.$ no colony growth at $0.2 \mu \mathrm{g} / \mathrm{ml}$ a.i. $)$ whereas the isolates from the site with prior exclusive use showed growth at DMI concentrations 3 to $>100$ times higher, and were rated as DMI resistant $\left(\mathrm{DMI}^{\mathrm{R}}\right)$. A second survey examined 1,530 monoconidial isolates, including 1,143 from 62 orchard sites in Michigan, where DMIs had been used to control CLS. Resistance to fenbuconazole was detected in $99.7 \%$ of the orchard isolates. All isolates from wild cherry trees were sensitive and isolates from feral and dooryard trees showed a range of sensitivities. A polymerase chain reaction (PCR)-based detection method for identifying $B$. jaapii and $\mathrm{DMI}^{\mathrm{R}}$ was developed and tested. The species-specific primer pair $(\mathrm{Bj}-$ $\mathrm{F}$ and $\mathrm{Bj}-\mathrm{R}$ ) based on introns in the CYP51 gene of B. jaapii, and the DMI ${ }^{\mathrm{B}}$-specific primer pair (DMI-R-Bj-F and DMI-R-Bj-R) based on an insert found upstream of CYP51 in all DMI ${ }^{\mathrm{R}}$ isolates, provided an accurate and rapid method for detecting $\mathrm{DMI}^{\mathrm{R}}$ B. jaapii. The PCR-based identification method will facilitate timely decision making and continued monitoring of $\mathrm{DMI}^{\mathrm{R}}$ subpopulations in response to management programs.
\end{abstract}

Fungicides often are essential for the production of crops of suitable quality and quantity for viable economic return. Prior to 1970, most fungicides were multisite inhibitors that functioned through interfering with metabolic pathways. These multisite fungicides typically inhibited spore germination and were used as protectants. The development of fungi resistant to these compounds was uncommon and the risk of resistance development is still considered to be very low. In the late 1960s, new types of fungicides were introduced and used widely. These site-specific fungicides disrupt a single metabolic process or structural site, and many show systemic activity that can mitigate losses with postinfection application. However, with the expanded use of

\section{Corresponding author: G. W. Sundin; E-mail address: sundin@msu.edu}

* The $\boldsymbol{e}$-Xtra logo stands for "electronic extra" and indicates that the online version contains supplemental material not included in the print edition. The online version contains a table describing the detection of isolates of Blumeriella jaapii resistant to sterol demethylation inhibitor fungicides using a polymerase chain reaction method.

DOI: 10.1094/PHYTO-96-0709

(C) 2006 The American Phytopathological Society site-specific fungicides in the 1970s, the evolution of fungicideresistant phytopathogen populations became a more common phenomenon.

The intensive use of site-specific fungicides in agricultural production, which typically involves multiple applications over wide areas, provides a potent selective mechanism for increasing the frequency of fungicide-resistant isolates within populations. In any population of fungi there may be, at very low frequencies, individuals resistant to the site-specific fungicide. This resistance can be due to mutations of a single gene. The frequency of resistant individuals in the population can increase due to the selective pressure of extensive fungicide use and, as a result, a resistant subpopulation may develop. The presence of this subpopulation at a site may lead to a reduced level of disease control in the field, or "practical resistance" (16). The development of fungal populations with demonstrated reduced sensitivity or resistance has been documented with several groups of site-specific fungicides: benzimidazoles, carboximides, dodine, sterol demethylation inhibitors (DMIs), and stobilurins $(2,19)$.

DMI fungicides inhibit the sterol C-14 $\alpha$-demethylation of 24methylenehydrolanosterol, a precursor of ergosterol, a critical fungal cell membrane component (2). Several fungi with reduced 
sensitivity to DMIs have been characterized, including plant pathogens such as Cercospora beticola (13), Monilinia fruticola (31), Mycosphaerella fijiensis (25), Penicillium digitatum (9), Podosphaera xanthii (23), Rynchosporium secalis (15), Sclerotinia homoeocarpa (7), Sphaerotheca fuliginea (22), Uncinula necator (8), Venturia inaequalis $(17,18,27,28)$, and the human pathogen Candida albicans (6). Molecular mechanisms of DMI resistance have been studied intensively with three main mechanisms identified, including (i) mutations in the DMI target enzyme, 14 $\alpha$-demethylase (CYP51), leading to a decreased affinity of DMIs to the target protein $(1,3,4)$; (ii) overexpression of the CYP51 gene leading to increased production of the target enzyme $(10,26)$; and (iii) overexpression of ATP-binding cassette (ABC) transporters encoding efflux pumps $(11,32)$.

DMI fungicides have been used in Michigan cherry orchards since their introduction beginning in 1987 and were used by $96 \%$ of growers queried in a recent survey (J. Haley, personal communication). Two main diseases, brown rot and cherry leaf spot (CLS), are targeted with DMIs; of these, CLS, caused by the fungus Blumeriella jaapii (Rehm) Arx, is the most important disease of tart cherry (Prunus cerasus L.) and a major disease of sweet cherry $(P$. avium L.) in Michigan and the Great Lakes region of North America. The early defoliation caused by CLS leads to poor fruit quality, reduced fruit bud survival, and increased tree mortality during severe winters. The primary method of CLS management is through the use of fungicides. Current control recommendations call for five to seven fungicide applications per season to reduce leaf spot infection and prevent infection-mediated premature defoliation. In recent years, however, the observations of growers, extension agents, and research results have suggested the reduced efficacy of DMIs for controlling CLS compared with previous years (12,29). In 2003, a sweet cherry orchard located in Benzie County, MI, in which the DMI fungicide fenbuconazole was applied exclusively for the previous 8 years was brought to our attention. This orchard had suffered catastrophic tree losses due to winter injury after the 2002 season, when fenbuconazole failed to control CLS and trees in the orchard were defoliated early in the summer. Based on these observations and previous reports of resistance to DMIs in other phytopathogenic fungi, we hypothesized that $B$. jaapii populations in Michigan cherry orchards had developed resistance to DMI fungicides.

Given the importance of leaf spot to the cherry industry throughout the Great Lakes region, the widespread use of DMIs, anecdotal reports of reduced efficacy, and field trial results, further investigations were warranted. If resistant subpopulations of B. jaapii had developed, then it would be necessary to incorporate effective anti-resistance strategies into CLS control programs $(2,16,17)$. Determination of sensitivity of a pathogen to a fungicide is the first step in the management of fungicide resistance. Information on sensitivity and the dynamics of fungicide-resistant populations in the field can offer early warning of an impending resistance problem and can be used to develop and evaluate the effectiveness of resistance management programs. The current method for detecting DMI resistance in B. jaapii requires single-spore isolates and subsequent transfers to a medium containing the fungicide in question. For B. jaapii, this procedure is labor-intensive and timeconsuming, taking at least 2 months to get results because of the extreme slow growth of the pathogen in culture. Genetic polymerase chain reaction (PCR)-based detection of DMI resistance, based on alterations in the CYP51 target gene of resistant strains, have been developed for Penicillium digitatum (9). We hypothesized that the development of a similar PCR-based diagnostic tool for detection and analysis of DMI resistance in B. jaapii populations would enable us to provide growers with timely information regarding the occurrence of DMI resistance in their orchards.

The objectives of this study were to (i) determine the sensitivity to DMI fungicides of populations of B. jaapii from Michigan, (ii) examine the distribution of resistant and sensitive phenotypes of B. jaapii in orchards around the state, and (iii) develop a molecular method for the rapid detection of DMI-resistant $\left(\mathrm{DMI}^{\mathrm{R}}\right)$ B. jaapii.

\section{MATERIALS AND METHODS}

Efficacy of DMI fungicides in controlling CLS, 1989 to 2005. Field trials examining the efficacy of DMI fungicides in controlling CLS were conducted in an experimental tart cherry orchard (Prunus cerasus cv. Montmorency) located at the Northwest Michigan Horticultural Experiment Station in Leelanau County. The experiments were initiated in 1989 when the trees were 10 years old. Experiments utilizing tebuconazole (Elite 45 DF) were conducted between 1989 and 2005, with the exception of 1993 and 2004, and experiments utilizing fenbuconazole (Indar $75 \mathrm{~W}$ ) were conducted between 1996 and 2005, with the exception of 2004. Fungicide rates used were 170.1 and $56.7 \mathrm{~g} / \mathrm{ha}$ for Elite $45 \mathrm{DF}$ and Indar $75 \mathrm{~W}$, respectively. In each year, six or seven fungicide sprays were applied to trees at approximately 10-day intervals, with the first spray applied at the late bloom to early petal fall stage of fruit bud development. The experimental design was a randomized complete block using single-tree plots with four replications per treatment. The treatments were re-randomized each year. Fungicides were applied with a handgun sprayer at 300 to 350 psi and 458.9 liters of water per hectare. Leaf spot ratings typically were conducted in late August or early September by assessing infection on terminals. In all, 10 terminals per tree were rated in experiments from 1989 to 1997, and 20 terminals per tree were rated in experiments from 1998 to 2005.

Isolate collection. Randomly selected cherry leaves infected with $B$. jaapii were collected and used as a source of monoconidial isolates. Cirrhi from sporulating acervuli were streaked on to $2 \%$ water agar and incubated for $24 \mathrm{~h}$ at 23 to $25^{\circ} \mathrm{C}$. Individual germinated conidia then were transferred and maintained on MMEA plates (2\% malt extract, $0.1 \%$ yeast extract, $2 \%$ agar) at 23 to $25^{\circ} \mathrm{C}$. B. jaapii is an extremely slow-growing fungus; several culture media were tested, and MMEA supported the greatest amount of growth and sporulation. Despite the increased growth on MMEA, monoconidial isolates produced colonies only a few millimeters in diameter after 2 weeks of growth.

In 2003, three categories of sites containing tart and sweet cherry trees were surveyed (survey 1): the commercial sweet cherry orchard in Benzie County, MI where the DMI fenbuconazole had been used exclusively for 8 years; Michigan State University (MSU) experimental orchards where DMIs had been used in fungicide trials since 1989 (over the years reported, all of these trees had been treated at least once with DMIs either alone or in combination with other fungicides); and sites where there was no known history of DMI use, dooryard trees near Salem, $\mathrm{OH}$, and an abandoned sweet cherry orchard in Berlin Center, $\mathrm{OH}$. A few B. jaapii isolates from wild black cherry (P. serotina Ehrh.) growing near Salem, $\mathrm{OH}$ also were collected for testing.

In the expanded survey of 2004 (survey 2), the tested isolates were collected from cherry trees in 62 orchards, 49 of which were commercial orchards in the four major cherry-producing regions of Michigan: Traverse City, Benzie, Hart/Shelby, and Southwest. Isolates also were collected from additional sites, including orchards from the research facilities of MSU in the Mid-Michigan area, the abandoned Ohio orchard, and a commercial orchard located in eastern Michigan. Additional isolates from dooryard trees and other cherry species, black cherry ( $P$. serotina), choke cherry ( $P$. virginiana $L$.), pin cherry ( $P$. pensylvanica L.f.), mahaleb cherry ( $P$. mahaleb L.), and dwarf European cherry ( $P$. fruticosa Pallas), were collected from within or adjacent to orchards or from remote sites in Michigan and Ohio.

Determination of sensitivity of B. jaapii to DMIs. DMI fungicides do not appreciably affect spore germination, and previous 
studies, conducted by other researchers, were based on reduced mycelial growth $(7,18,20,28)$. There are two valid approaches to measure the mycelial growth responses to DMIs: one is quantitative, the concentration of fungicide required to reduce growth by $50 \%\left(\mathrm{EC}_{50}\right)$; the other is qualitative, the minimum concentration required to completely inhibit colony growth (minimum inhibitory concentration $[\mathrm{MIC}])(7,18,20,28)$. In this study, we used the qualitative MIC method.

Survey 1, 2003. The sensitivity of $B$. jaapii to four DMI fungicides was tested: fenbuconazole (Indar75 WSP, Dow Agrosciences), tebuconazole (Elite 45 DF, Bayer), myclobutanil (Nova 40W, Dow Agrosciences), and fenarimol (Rubigan EC, Gowan). The fungicides were dissolved in $95 \%$ ethanol to prepare stock solutions. Aliquots of stock solution were added to MMEA after the medium was sterilized and cooled to $40^{\circ} \mathrm{C}$. The concentration of active ingredient (a.i.) for each of the tested fungicides was adjusted to $0.2,0.4,0.6,0.8,1.0,2.0,3.0,4.0,5.0,10.0$, and $20.0 \mu \mathrm{g} / \mathrm{ml}$. MMEA $+0.2 \%$ ethanol (equal to the amount of ethanol in highest concentration of a.i.) was used as a control. Thus, the isolates were tested against a total of 45 treatments (four fungicides by 11 concentrations of a.i. and the control).

Mycelial plugs $(1 \mathrm{~mm})$ from each of 137 tested monoconidial isolates were transferred to the DMI test plates. More than 40 isolates from each of the three test groups (the DMI exclusive orchard, experimental orchards with a mixed history of DMI use, and no known DMI history) were screened. Two replicates of each isolate were examined. After 21 days of incubation at 23 to $25^{\circ} \mathrm{C}$, the plates were examined for colony growth and the MIC of fungicide required for each isolate was recorded. The MIC value reported was the minimum concentration necessary to completely inhibit both replicates. The results from survey 1 were used to establish the test concentrations used in survey 2.

Survey 2, 2004. The primary goal of this survey was to examine the distribution and frequency of DMI phenotypes in commercial cherry orchards in Michigan. In this survey, a single DMI, fenbuconazole, was used. The DMI test medium was prepared as described in survey 1 . Discriminatory rates of fenbuconazole were set at $0,0.2,3.0$, and $5.0 \mu \mathrm{g} / \mathrm{ml}$ a.i. A phenotypic sensitivity rating was assigned based on colony growth at the tested concentrations. Mycelial plugs ( $1 \mathrm{~mm}$ ) from each of the tested monoconidial isolates were transferred to the DMI test plates. In all, 1,530 monoconidial isolates were tested, with the number of isolates from a site ranging from 8 to 20 . Two replicates of each isolate were examined. After incubation for 21 days at 23 to $25^{\circ} \mathrm{C}$, the plates were examined for colony growth and sensitivity ratings were as described in survey 1.

Development of a species-specific PCR primer pair for detecting B. jaapii. CLS and B. jaapii are relatively easy to identify on host tissue, but the extremely slow-growing fungus is difficult to isolate and identify in culture. Several weeks are required before an experienced observer can identify cultures of $B$. jaapii. Because of this, a pair of species-specific PCR primers, Bj-F (5'TCAGTTGCTTTCTGATGAGGA) and Bj-R (5'-AGAGTCAGCACCCAGCGATTT), were developed. The primer sequences were based on the sequences of two introns in the $14 \alpha$-demethylase (CYP51) gene from B. jaapii (21). The efficacy of this primer pair for identifying $B$. jaapii was examined by testing on 78 isolates of $B$. jaapii collected from tart and sweet cherry, 1 isolate from mahaleb, and 1 from black cherry. The isolates were selected to represent the geographic distribution of $B$. jaapii collected in survey 2. Eighteen other fungal isolates, most recovered from cherry samples, including Alternaria sp., Armillaria ostoyae, Botryosphaeria obtusa, Botrytis cinerea, Cryptosporiopsis sp., Cylindrocarpon sp., Cytospora sp., Fusarium sp., Leucostoma persoonii, Monilinia fructicola, Penicillium sp., Scytinostroma galacatinum, Trichoderma sp., Venturia inaequalis, Xylaria polymorpha, and three unidentified fungal isolates, were used to test the specificity of this primer pair.
Development of genotype-specific PCR primers for detecting $\mathbf{D M I}^{\mathrm{R}}$ isolates of $\boldsymbol{B}$. jaapii. A 2,120-bp insert was found upstream of the CYP51 gene in DMI ${ }^{\mathrm{R}}$ isolates (isolates not rated as sensitive to DMI fungicides in survey 2), but not in DMIsensitive $\left(\mathrm{DMI}^{\mathrm{S}}\right)$ isolates (isolates rated as sensitive in survey 2) (21). This insert was sequenced, and a pair of PCR primers, DMIR-Bj-F (5'-TTGTACAGAGCAAGGCATGCG) and DMI-R-Bj-R (5'-TGTAGGGGAAGGGCTCAAATA), was developed for the amplification of the insert sequence from $\mathrm{DMI}^{\mathrm{R}}$ isolates. The forward primer DMI-R-Bj-F was located in a region upstream of the 2,120-bp insert, and the reverse primer DMI-R-Bj-R was located in the $5^{\prime}$ end of the insert. To test the specificity of this primer pair, we used a collection of B. jaapii isolates from the pool of 1,530 isolates collected throughout Michigan and Ohio.

For rapid identification of $B$. jaapii and of $\mathrm{DMI}^{\mathrm{R}}$ isolates by PCR using the species-specific primer pair $B j-F$ and $B j-R$ and genotype-specific primer pair DMI-R-Bj-F and DMI-R-Bj-R, respectively, DNA from the mycelium of each isolate was extracted by a simple boiling method. Briefly, approximately $2 \mathrm{mg}$ (fresh weight) of mycelium was collected by gently scraping the surface of a culture on MMEA medium with a sterilized loop, placed into a $1.5-\mathrm{ml}$ microcentrifuge tube containing $30 \mu \mathrm{l}$ of $1 \mathrm{M}$ Tris- $\mathrm{HCl}$ ( $\mathrm{pH} 8.0$ ), and overlaid with two drops of mineral oil. Samples were boiled at 98 to $100^{\circ} \mathrm{C}$ for $15 \mathrm{~min}$ and immediately placed on ice for $5 \mathrm{~min}$. After centrifugation at $10,000 \times g$ for 2 min, $2 \mu$ of supernatant below the oil was used as template DNA in a PCR amplification.

PCR amplifications were performed in a $50-\mu$ reaction volume containing $1 \times$ PCR buffer, $2 \mathrm{mM} \mathrm{MgCl}_{2}, 0.75 \mathrm{mM}$ each dNTP, 1 pmol of each primer, $1.0 \mathrm{U}$ of Taq polymerase, and $2 \mu \mathrm{l}$ of supernatant from the boiled mycelium solution. The PCR amplifications were conducted using the following parameters: one cycle at $94^{\circ} \mathrm{C}$ for $5 \mathrm{~min} ; 35$ cycles at $94^{\circ} \mathrm{C}$ for $1 \mathrm{~min}, 60^{\circ} \mathrm{C}$ (primer pairs $\mathrm{Bj}-\mathrm{F}$ and $\mathrm{Bj}-\mathrm{R}$, DMI-R-Fj-F and DMI-R-Bj-R) or $55^{\circ} \mathrm{C}$ (primer pair ITS1-Fungal and ITS2) for $1 \mathrm{~min}$, and $72^{\circ} \mathrm{C}$ for $1.5 \mathrm{~min}$; and a final extension at $72^{\circ} \mathrm{C}$ for $10 \mathrm{~min}$. A $10-\mu \mathrm{l}$ aliquot of each sample was analyzed by electrophoresis using $2 \%$ agarose gels.

Detection of $\mathrm{DMI}^{\mathrm{R}} B$. jaapii from naturally infected cherry leaves. The efficacy of PCR-based detection of $\mathrm{DMI}^{\mathrm{R}}$ B. jaapii directly from infected cherry leaves without fungal isolation and culturing also was tested. For this study, we used tart cherry leaves (30 to 50 per orchard) showing characteristic CLS lesions from six orchards (four commercial and two experimental) where DMIs had been used and reduced sensitivity had been confirmed in survey 2. A single leaf disk ( $3 \mathrm{~mm}$ in diameter) containing a CLS lesion was cut from each leaf, 30 to 50 samples from a site were pooled, and DNA was extracted using the FastDNA kit (Qiagen, Vista, CA) with the buffer cell lysis/DNA solubilizing solution for vegetation (CLS-VF) according to the manufacturer's protocol. To remove PCR inhibitors released from plant tissues, extracted DNA was suspended in $200 \mu \mathrm{l}$ of $\mathrm{H}_{2} \mathrm{O}$, and further purified with an addition of $200 \mu$ of the Binding Matrix Solution from the FastDNA kit. The purified DNA was resuspended in $30 \mu \mathrm{l}$ of water, and 2- $\mu \mathrm{l}$ aliquots of 1:10 DNA dilutions were used for PCR amplifications. The PCR amplifications were performed as described above using the primer pair DMI-R-Bj-F and DMI$\mathrm{R}-\mathrm{Bj}-\mathrm{R}$. DNA extracted from healthy leaves spiked with $1 \mathrm{ng}$ of fungal DNA extracted from $\mathrm{DMI}^{\mathrm{S}}$ isolate $\mathrm{AH} 1-4$ was used as a negative control.

\section{RESULTS}

Efficacy of DMI fungicides in controlling CLS. Efficacy trials with tebuconazole (Elite $45 \mathrm{DF}$ ) and fenbuconazole (Indar $75 \mathrm{~W}$ ) were conducted from 1989 to 2005 and 1996 to 2005, respectively, at the Northwest Michigan Horticultural Research Station. Tebuconazole programs provided excellent control of CLS infection from 1989 to 1994, with the first reduction in 
fungicide efficacy observed in 1995 (Fig. 1). From 1998 to 2002 and 2005, the level of CLS control in tebuconazole-treated trees was commercially unacceptable (Fig. 1). Similar results, indicating a reduction in efficacy of DMIs, were observed with fenbuconazole in experiments conducted between 1998 and 2005 (Fig. 1). The field trial results, which show reduced levels of control over time, indicate that practical resistance to DMIs has developed in this population of $B$. jaapii. The reduced efficacy observed was not limited to a single DMI, indicating cross-resistance to these two DMIs (tenbuconazole and fenbuconazole) in B. jaapii.

Sensitivity of B. jaapii to DMIs. Survey 1. In all, 216 monoconidial isolates were collected in 2003. From this pool of isolates, 137 were used in DMI sensitivity tests. Of the 42 isolates from sites in Ohio with no known DMI history, 41 were inhibited by all four tested DMIs at the lowest concentration tested $(0.2 \mu \mathrm{g} / \mathrm{ml}$ a.i.). In one isolate from Ohio (SM1-4), the MIC of myclobutanil was $0.4 \mu \mathrm{g} / \mathrm{ml}$ a.i.; however, this isolate was inhibited by the other three DMIs at $0.2 \mu \mathrm{g} / \mathrm{ml}$. Additionally, none of four isolates from unsprayed wild black cherry trees were able to grow at the lowest concentration $(0.2 \mu \mathrm{g} / \mathrm{ml})$ for each DMI.

The 46 isolates from the commercial orchard where fenbuconazole had been used exclusively and 45 from the MSU research orchards showed MICs covering a range of values (0.2 to $>20.0 \mu \mathrm{g} / \mathrm{ml}$ a.i.) (Fig. 2). However, only 1 of these 91 isolates was inhibited at the $0.2 \mu \mathrm{g} / \mathrm{ml}$ a.i. level, and that was for a single DMI (fenbuconazole). Cross-resistance was apparent for the four DMIs tested; isolates from the DMI-exclusive orchard, where only fenbuconazole was used, also showed reduced sensitivity to all of the other DMIs tested. In the in vitro tests fenbuconazole and tebuconazole generally were more effective at lower rates of a.i. against B. jaapii isolates than myclobutanil and fenarimol (Fig. 2). The isolates recovered from the commercial orchard where fenbuconazole had been used exclusively showed the highest levels of reduced sensitivity (Fig. 2). For fenbuconazole, $44.9 \%$ of isolates from this orchard were not inhibited at $5.0 \mu \mathrm{g} / \mathrm{ml}$ a.i. compared with only 8.7 and $0 \%$ of the isolates from the experimental MSU orchards and the Ohio orchard with no DMI history, respectively. Similar results were noted for tebuconazole: $87.0 \%$ of the isolates from this orchard were not inhibited at $5.0 \mu \mathrm{g} / \mathrm{ml}$ a.i. compared with 35.5 and $0 \%$ from the experimental and Ohio orchards. The response of the isolates to myclobutanil and fenarimol also followed this pattern. These in vitro results confirmed our hypothesis that B. jaapii populations in some Michigan orchards have developed resistance to DMI fungicides and indicate that the detected levels conferred practical resistance in the orchard, as evidenced by the catastrophic loss of the DMIexclusive orchard and the reduced efficacy of DMIs in the experimental orchard.

In both the field efficacy study and the in vitro study in survey 1 , there was evidence of cross-resistance to the DMIs tested. The fungicide fenbuconazole was selected as the representative DMI to test the reactions of B. jaapii to DMIs for the expanded 2004 survey 2 . The growth responses of $B$. jaapii to fenbuconazole in study 1 also were used to establish a phenotypic rating system for the in vitro sensitivity tests of study 2 . Isolates were categorized as sensitive, low moderate, high moderate, or resistant if the MIC values for fenbuconazole were $0.2,3.0,5.0$, or $>5.0 \mu \mathrm{g} / \mathrm{ml}$ a.i., respectively. Because all of the isolates with no history of DMI exposure in this study had an MIC of $0.2 \mu \mathrm{g} / \mathrm{ml}$ a.i., for the PCR studies these were designated as $\mathrm{DMI}^{\mathrm{S}}$. Isolates with MICs above $0.2 \mu \mathrm{g} / \mathrm{ml}$ a.i. were designated as $\mathrm{DMI}^{\mathrm{R}}$.

Survey 2. In all, 1,530 monoconidial isolates were tested in this survey. Isolates were collected from unsprayed wild cherry trees, dooryard trees with no known history of DMI use, abandoned orchard sites with no known history of DMI use, and active orchards where DMIs have been used. Isolates of $B$. jaapii from unsprayed wild cherry trees (choke, black, and pin cherry) in Michigan and Ohio were examined. All 251 monoconidial isolates from these wild hosts tested were sensitive to DMIs. Many of the wild cherry trees sampled in Michigan were located adjacent to orchards where DMIs were used or in communities with active orchards. On MMEA, the isolates from black and choke cherry produced colonies that were distinctly whiter in appearance and produced spore cirrhi that were a deeper salmon color than colonies of $B$. jaapii isolated from the other cherry hosts. Pin cherry isolates resembled isolates from tart and sweet cherry.

Isolates of B. jaapii also were collected from dooryard tart and sweet cherry trees. All of the dooryard isolates were similar in appearance on MMEA to the isolates from orchard trees. Of these isolates, the 33 from four locations in Ohio were rated as sensitive, whereas the 51 dooryard isolates from four locations in Michigan showed a range of sensitivities (Table 1). No Ohio samples came from trees near commercial orchards; however, the

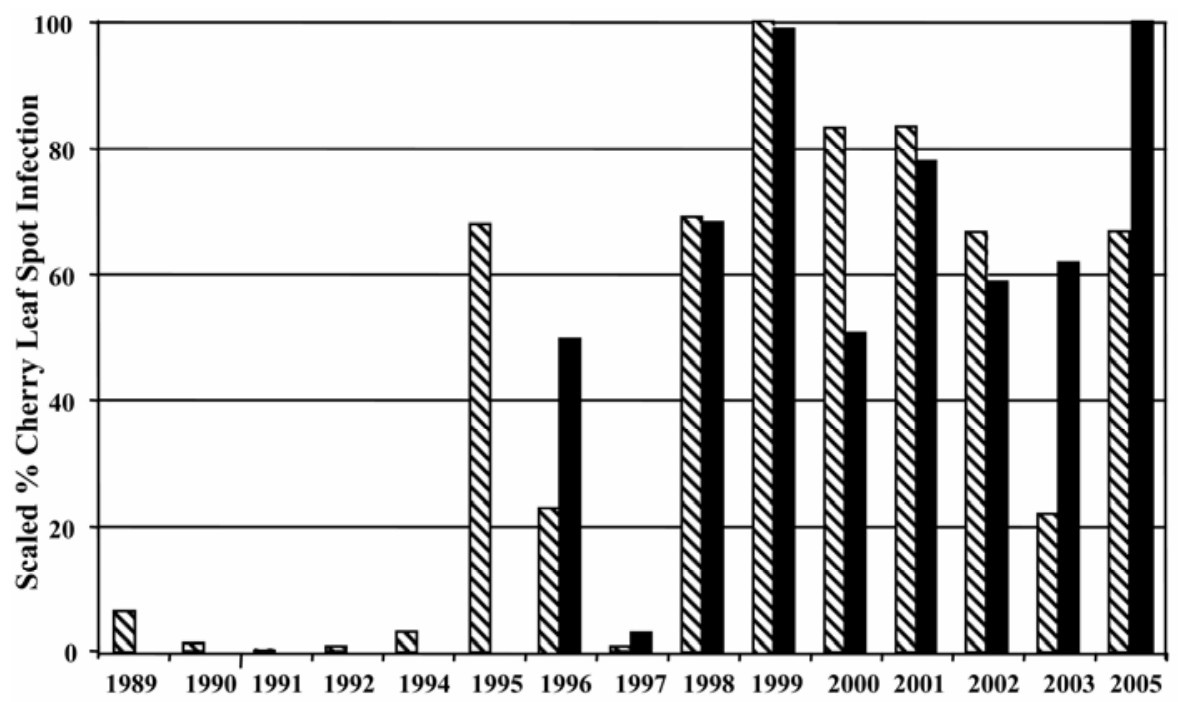

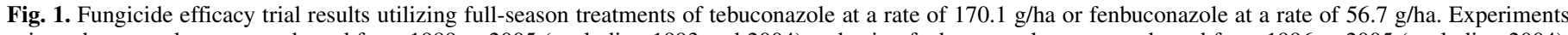

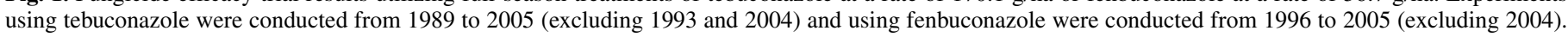

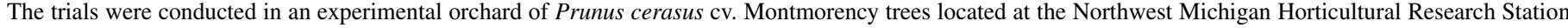

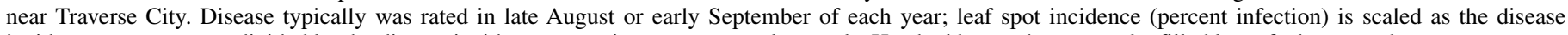
incidence per treatment divided by the disease incidence occurring on unsprayed controls. Hatched bars, tebunconazole; filled bars, fenbuconazole. 
dooryard trees in Michigan were located in communities with currently active orchards. The 27 isolates from an abandoned sweet cherry orchard in Ohio, with no known history of DMI use, were all sensitive. The 25 isolates from feral tart and mahaleb cherry trees growing at abandoned orchard sites in Michigan, where past DMI use was possible and where active orchards were in the community, showed a range of sensitivity responses. Of these isolates, $48 \%$ were sensitive, which is much higher than the level of sensitive isolates from commercial orchards $(0.3 \%)$, and $52 \%$ were rated as high moderate or resistant (Table 1).
In all, 1,143 monoconidial isolates of B. jaapii were recovered from 49 commercial orchard blocks and 12 other orchard sites in 2004. The four main cherry-growing regions along Lake Michigan were sampled as well as outlying experimental orchards in central Michigan and a commercial orchard in eastern Michigan (Fig. 3). Reduced sensitivity to the DMI fenbuconazole was common among the orchard isolates, with 45.4, 29.1, and $25.2 \%$ being rated as low moderate, high moderate, and resistant, respectively (Table 2). Only $0.3 \%$ of the isolates recovered from these orchards, where DMIs have been used, were rated as sensitive to
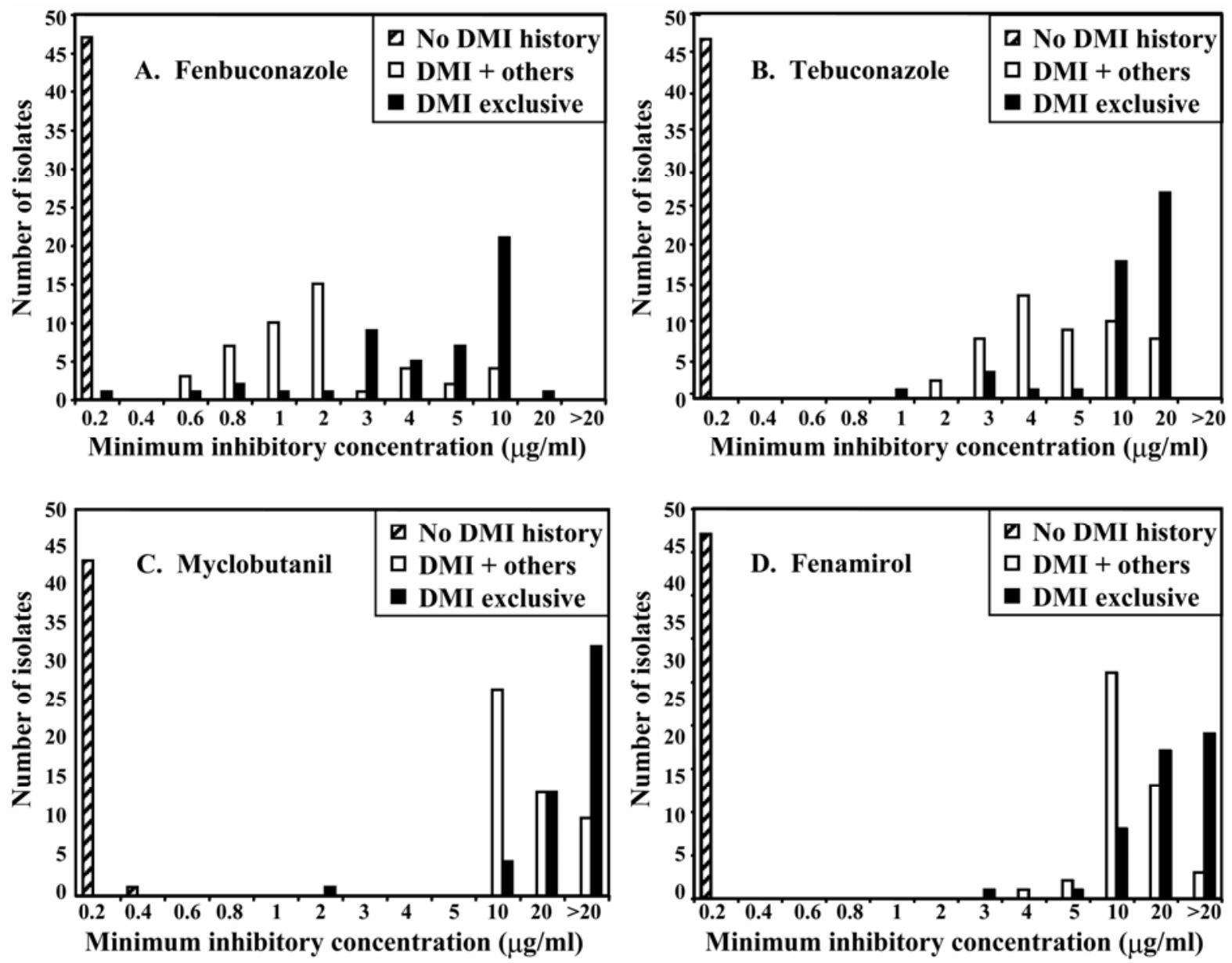

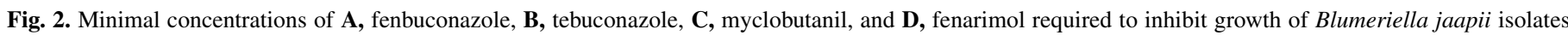

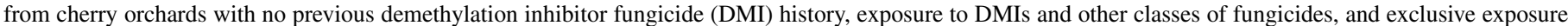
to DMIs for 8 previous years.

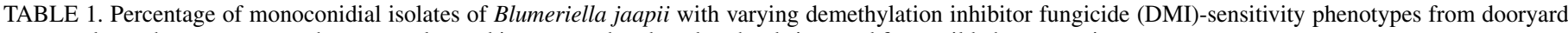
sweet and tart cherry trees, tart cherry trees located in or near abandoned orchard sites, and from wild cherry species

\begin{tabular}{|c|c|c|c|c|c|c|}
\hline \multirow[b]{2}{*}{ Location or species } & \multicolumn{2}{|c|}{ Number of } & \multicolumn{4}{|c|}{ B. jaapii DMI-sensitivity phenotypes $(\%)^{\mathrm{a}}$} \\
\hline & Sites & Isolates & Sensitive & Low moderate & High moderate & Resistant \\
\hline \multicolumn{7}{|l|}{ Dooryard sites } \\
\hline Michigan & 4 & 51 & 33.3 & 43.1 & 5.9 & 17.6 \\
\hline Ohio & 4 & 33 & 100.0 & 0.0 & 0.0 & 0.0 \\
\hline Total & 8 & 84 & $59.5(50)$ & $26.2(22)$ & $3.6(3)$ & $10.7(9)$ \\
\hline \multicolumn{7}{|l|}{ Abandoned orchards } \\
\hline Michigan & 4 & 25 & 48.0 & 0.0 & 32.0 & 20.0 \\
\hline Ohio & 4 & 27 & 100.0 & 0.0 & 0.0 & 0.0 \\
\hline Total & 8 & 52 & $75.0(39)$ & $0.0(0)$ & $15.4(8)$ & $9.6(5)$ \\
\hline \multicolumn{7}{|l|}{ Wild cherry species } \\
\hline Choke cherry & 4 & 38 & 100.0 & 0.0 & 0.0 & 0.0 \\
\hline Pin cherry & 4 & 26 & 100.0 & 0.0 & 0.0 & 0.0 \\
\hline Black cherry & 4 & 187 & 100.0 & 0.0 & 0.0 & 0.0 \\
\hline Total & 12 & 251 & $100.0(251)$ & $0.0(0)$ & $0.0(0)$ & $0.0(0)$ \\
\hline
\end{tabular}

a Numbers in parentheses are the total number of isolates in each phenotypic category. 
fenbuconazole (Table 2). The Southwest Michigan cherry-growing region had a lower percentage of isolates phenotypically rated as resistant compared with the other cherry-growing regions (Table 2). We used $\chi^{2}$ analysis to examine the relative proportion of the populations from each growing region rated as resistant. When comparing the Southwest Michigan populations with the other regions, $\chi^{2}$ values $>270\left(P<10^{-4} ; 1 \mathrm{df}\right)$ were obtained, indicating that the distribution of DMI phenotypes in this region was significantly different than the other regions. Among the other regions, $\chi^{2}$ values for this same comparison ranged from 0.002 to $2.514(0.1180<P<0.9664 ; 1 \mathrm{df})$, indicating that the distribution of the DMI phenotypes was not significantly different at the $P=0.05$ level.

Among the orchard isolates of $B$. jaapii tested, 39 were from Prunus mahaleb, the most common rootstock for tart cherry, and 7 were from $P$. fruiticosa trees that were intermixed with tart and sweet cherry isolates in a research block. These isolates resembled the tart and sweet cherry isolates in culture and also showed various levels of reduced sensitivity to DMIs.

Identification of $B$. jaapii species by a PCR method. The Bj$\mathrm{F}$ and $\mathrm{Bj}-\mathrm{R}$ primer pair consistently generated a 295-bp fragment from each of 79 isolates of $B$. jaapii that were isolated from orchard trees (tart, sweet, and mahaleb) across the region. The

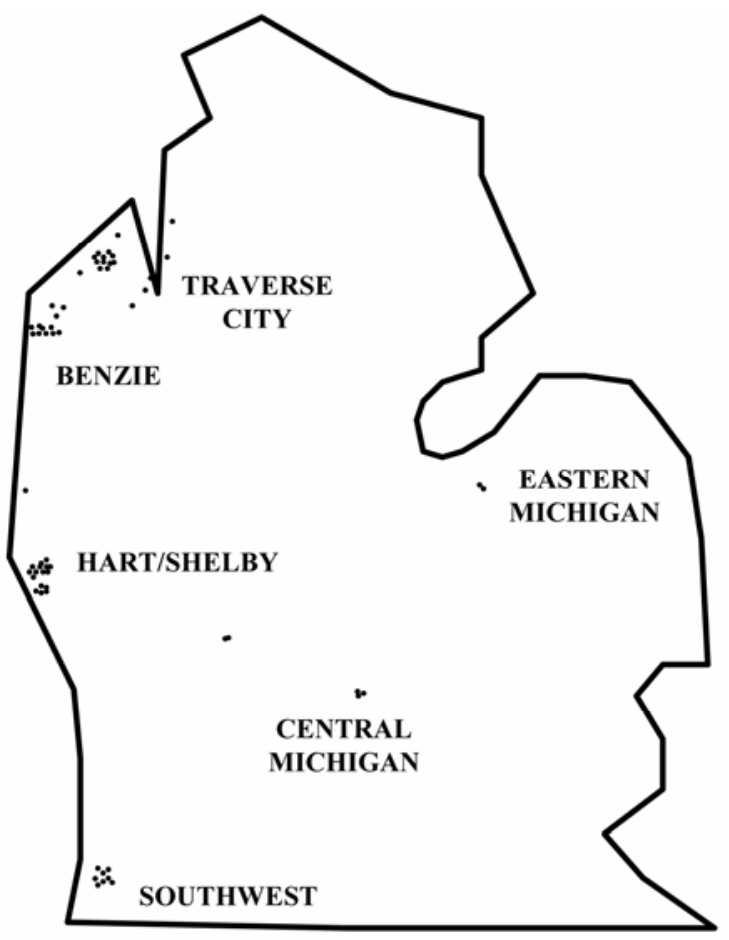

Fig. 3. Orchard locations in Michigan from which isolates of Blumeriella jaapii were recovered. Important tart cherry-producing regions are labeled. single isolate from black cherry, which in culture is distinct from the orchard isolates, also produced the 295-bp fragment. None of the other 18 isolates from other fungal species examined produced the fragment (Fig. 4A).

PCR-based identification of $\mathrm{DMI}^{\mathrm{R}}$ isolates of $\boldsymbol{B}$. jaapii. The primer pair DMI-R-Bj-F and DMI-R-Bj-R generated two different sizes of PCR products (434 or $344 \mathrm{bp}$ ) from the $\mathrm{DMI}^{\mathrm{R}}$ isolates (Fig. 4B). DNA sequencing of these PCR fragments revealed that the size differential was due to the position location of the insert (102 or 181 bp before the start codon) upstream of CYP51, and an additional 20-bp deletion of the insert when it was located $181 \mathrm{bp}$ upstream of the CYP51 start codon in the isolates RSS-2 and SIT9-3 (Z. Ma, unpublished data). Using this pair of PCR primers, the 434-bp PCR product was detected in 56 of $58 \mathrm{DMI}^{\mathrm{R}}$ isolates, and the 344-bp PCR product was detected in the two remaining $\mathrm{DMI}^{\mathrm{R}}$ isolates, RSS-2 and SIT9-3 (Table 3). PCR products were not generated from any $\mathrm{DMI}^{\mathrm{S}}$ isolates of $\mathrm{B}$. jaapii examined (Table 3 ) or from 18 other fungal species tested by this pair of PCR primers (data not shown). Additionally, using the DMI-R-Bj-F and DMI-R-Bj-R primer pair, either 434- or 344-bp fragments were amplified from DNA extracted directly from naturally infected leaves (Fig. 4C). The nucleotide sequence of the PCR products was verified to confirm that the bands represented B. jaapii DNA sequences.

\section{DISCUSSION}

The results of our field studies and surveys confirmed that (i) the efficacy of DMI fungicides in controlling CLS has decreased over the years since their introduction at the experimental orchard, (ii) cross-resistance to four DMI fungicides (fenbuconazole, tebuconazole, myclobutanil, and fenarimol) exists in populations of B. jaapii in Michigan, and (iii) the frequency of isolates with resistance to DMIs is higher in commercial orchards with a history of DMI use than in wild or unsprayed trees. A fenbuconazole rate of $0.2 \mu \mathrm{g} / \mathrm{ml}$ a.i. proved to be a working discriminatory concentration for detecting resistance in vitro. Isolates with resistance to DMIs were not inhibited at fungicide rates 3 to $>100$ times the concentrations needed to inhibit sensitive isolates. Subsequent tests done in our lab with 22 randomly selected sensitive isolates showed inhibition by rates of $0.02 \mu \mathrm{g} / \mathrm{ml} \mathrm{a.i.,} \mathrm{which} \mathrm{in-}$ creases even further the difference between sensitive and resistant isolates.

The occurrence of isolates with reduced sensitivity to DMIs in the laboratory is more widely demonstrated than practical resistance in the field (20). Baseline sensitivity studies with other fungi have shown that, even in a population unexposed to DMIs, there is a range of sensitivities among isolates $(5,20,24,27)$. Practical resistance, as defined by Köller, occurs when the frequency of $\mathrm{DMI}^{\mathrm{R}}$ isolates within a population is high enough to result in unsatisfactory disease control in the field (16). In our surveys, isolates of B. jaapii with reduced sensitivity to DMI fungicides were recovered from every commercial orchard site sampled in

TABLE 2. Percentage of monoconidial isolates of Blumeriella jaapii with varying demethylation inhibitor fungicide (DMI)-sensitivity phenotypes from commercial and experimental cherry orchards in Michigan

\begin{tabular}{|c|c|c|c|c|c|c|}
\hline \multirow[b]{2}{*}{ Region } & \multicolumn{2}{|c|}{ Number of } & \multicolumn{4}{|c|}{ B. jaapii DMI-sensitivity phenotypes $(\%)^{\mathrm{a}}$} \\
\hline & Orchards & Isolates & Sensitive & Low moderate & High moderate & Resistant \\
\hline Traverse City & 21 & 297 & 0.0 & 49.1 & 23.6 & 27.3 \\
\hline Benzie & 9 & 298 & 0.3 & 37.2 & 34.2 & 28.2 \\
\hline Southwest & 8 & 139 & 1.4 & 91.4 & 5.0 & 2.2 \\
\hline Mid-Michigan & 5 & 142 & 0.0 & 21.8 & 44.4 & 33.8 \\
\hline Eastern Michigan & 2 & 38 & 0.0 & 57.9 & 15.8 & 26.3 \\
\hline
\end{tabular}

a DMI-sensitivity phenotypes were based on the concentration of fenbuconazole $(\mu \mathrm{g} / \mathrm{ml}$ a.i. $)$ at which growth was inhibited. Sensitive $=0.2$, low moderate $=3.0$, high moderate $=5.0$, and resistant $=>0.5$ a.i. $\mu \mathrm{g} / \mathrm{ml}$. Numbers in parentheses are the total number of isolates in each phenotypic category. 
Michigan with a history of DMI use. Survey 1 showed that the frequency and level of DMI resistance was highest at the site where fenbuconazole had been used exclusively for the previous 8 years. Despite applications of fenbuconazole in 2002, CLS control failed in this orchard and trees were lost due to winter injury. The number of $\mathrm{DMI}^{\mathrm{R}}$ isolates also was higher in the MSU research orchards than in populations sampled from sites with no DMI history. Fungicide field trial data has shown the reduced efficacy of DMI fungicides over the years at one of the research sites. These combined results support the case for practical field resistance to DMIs in populations of B. jaapii in Michigan. The results of survey 1 also could be used to suggest a threshold value for practical resistance. In the isolates from the experimental orchard, the frequency distribution for the four phenotypic classes (sensitive/low moderate/high moderate/resistant) was approximately $0: 78: 13: 9 \%$, respectively. This population composition resulted in practical resistance in the field. In comparison, the frequency in the orchard where control failed was 2:29:24:45\%.

The distribution of $\mathrm{DMI}^{\mathrm{R}}$ phenotypes was not uniform among the isolates from the different cherry-growing regions of Michigan. The results shown in Table 2 do show, however, that, in looking at the proportion of high moderate and resistant isolates, the apparent threshold values found in the experimental orchard are surpassed in all but one of the cherry-growing regions tested. This would seem to confirm the reports of growers and extension agents that the DMIs are not working as effectively as in the past. The occurrence of high moderate and resistant isolates was lower in the Southwest compared with the other state cherry-growing regions. The reason for the difference is unclear at this time; however, comparisons of fungicide application programs between the growing regions may provide insight into how to delay the onset of practical resistance. Based on the results of our survey, DMIs now should be omitted from spray programs for controlling CLS in Michigan. Depending on the fitness of $\mathrm{DMI}^{\mathrm{R}}$ isolates of B. jaapii, which is unknown at this time, reducing DMI use may lead to a shift back toward sensitivity and the future feasibility of once again using this important class of fungicides for CLS control.

All isolates tested from black, pin, and choke cherry trees were sensitive to DMI fungicides. These cherry species grow wild in the cherry-growing regions of Michigan and can be found at the edges of orchards. Even isolates recovered from trees directly adjacent to rows of tart cherry that had been treated with DMIs failed to show any reduced sensitivity to DMIs. Previous inoculation studies (30) have suggested that there are differences between $B$. jaapii isolates from these wild hosts when compared with isolates from tart and sweet cherry. The appearance on MMEA medium of the isolates from black and choke cherry we collected was distinct from that of isolates from the other cherry hosts. Future studies examining B. jaapii and these apparent subgroups within the species are warranted. It does not appear that the wild cherry isolates are serving to move DMI resistance from the orchard sites. It also appears they may play no or only a limited role in serving as a source of DMI sensitivity to reintroduce into the orchards. P. mahaleb is the common rootstock for tart cherry trees. Previous inoculation studies have grouped isolates from mahaleb with those from tart and sweet cherry (29) and similar results were noted in this study, based on colony traits and the occurrence of $\mathrm{DMI}^{\mathrm{R}}$ isolates from mahaleb cherry found within and near orchards. Similarly, $\mathrm{DMI}^{\mathrm{R}}$ isolates also were recovered from $P$. fruticola trees growing intermixed with sweet and tart cherry lines at the Clarksville Research Station.

The distribution of DMI sensitivity differed in the dooryard and feral tart and mahaleb cherry trees sampled in Ohio versus Michigan. All of the isolates from Ohio were sensitive and came from sites away from active commercial orchards; these isolates were considered to offer a baseline sensitivity to compare against.

\section{A}

$\begin{array}{lllllllllllll}1 & 2 & 3 & 4 & 5 & 6 & 7 & 8 & 9 & 10 & 11 & 12\end{array}$

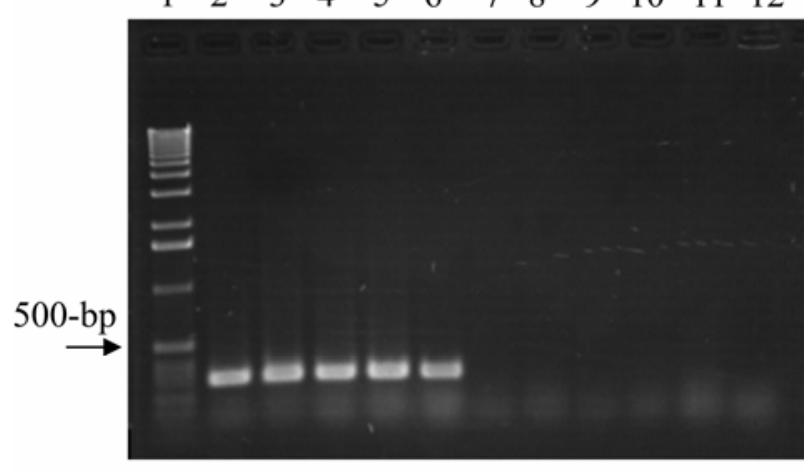

B
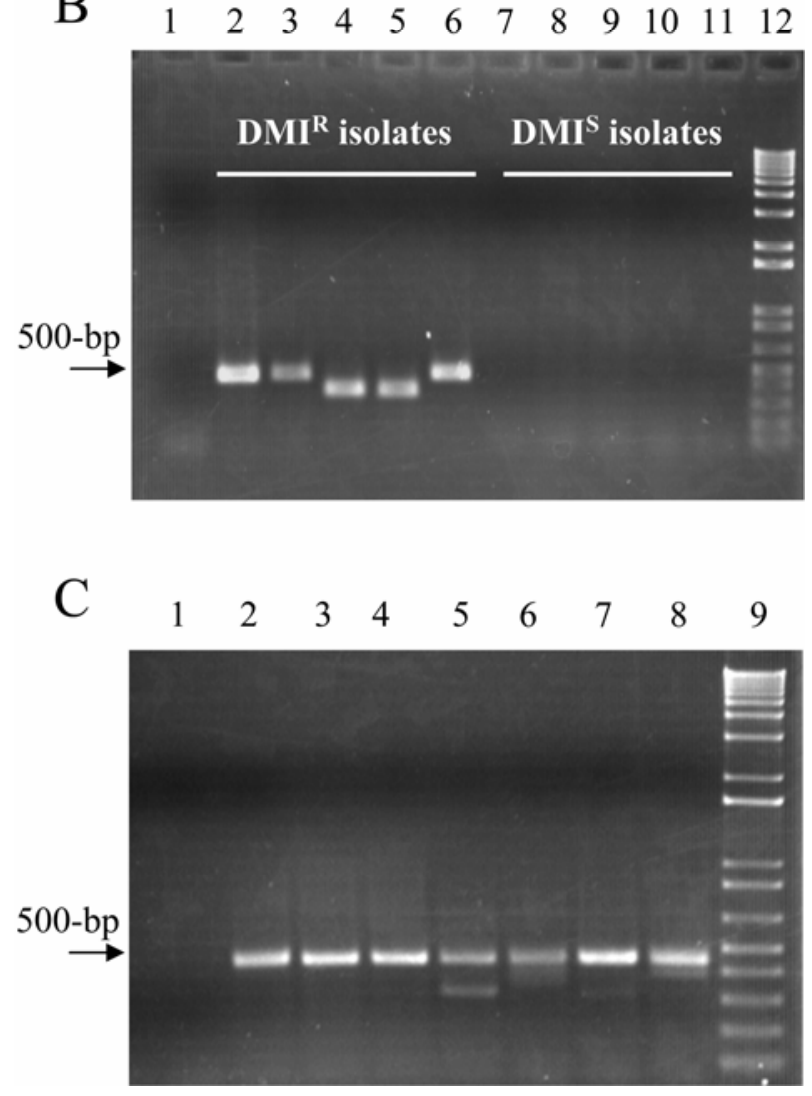

Fig. 4. A, Polymerase chain reaction (PCR) detection of Blumeriella jaapii using the species-specific oligonucleotide primer pair $\mathrm{Bj}-\mathrm{F}$ and $\mathrm{Bj}-\mathrm{R}$. Representative positive PCR reactions with five $B$. jaapii isolates are shown as well as a nontemplate control and representative PCR reactions using other fungi. Lane 1, molecular size markers; lane 2, B. jaapii SIT4-8; lane 3, B. jaapii RSS-2; lane 4, B. jaapii MF01-3; lane 5, B. jaapii AH1-4; lane 6, B. jaapii SC-8; lane 7, Alternaria sp.; lane 8, Armillaria ostoyae; lane 9, Botrysphaeria obtusae; lane 10, Botrytis cinerea; lane 11, Fusarium sp.; and lane 12, negative control. B, PCR detection of DMI-resistant $\left(\mathrm{DMI}^{\mathrm{R}}\right)$ B. jaapii. The oligonucleotide primer pair DMI-R-Bj-F and DMI-R-Bj-R was used to generate a 434- or 344-bp fragment from $\mathrm{DMI}^{\mathrm{R}}$ isolates collected from different locations, but not from DMI-sensitive $\left(\mathrm{DMI}^{\mathrm{S}}\right)$ isolates of B. jaapii. The negative control is PCR amplification without template DNA. Lane 1, negative control; lane 2, B. jaapii SIT4-8; lane 3, B. jaapii SIT5-14; lane 4, B. jaapii SIT9-3; lane 5, B. jaapii RSS-2; lane 6, B. jaapii MF01-3; lane 7, B. jaapii AH1-4; lane 8, B. jaapii AH1-7; lane 9, B. jaapii DSC1-4; lane 10, B. jaapii RL6; lane 11, B. jaapii SC-8; and lane 12, molecular size markers. C, PCR detection of $\mathrm{DMI}^{\mathrm{R}}$ B. jaapii directly from infected tart cherry leaves. The oligonucleotide primer pair DMI-R-Bj-F and DMI-R-Bj-R was used, and template DNA was obtained from leaf disks containing cherry leaf spot lesions. Lane 1, water control; lanes 2 to 8 , lesion samples from leaves from the following orchards (and county location): 2, VB1 (van Buren); 3, Bz1 (Benzie); 4, Bz2 (Benzie); 5, L1 (Leelanau); 6, IN1 (Ingham); 7, BZ3 (Benzie); 8, VB2 (van Buren); and lane 9 , molecular size markers. 
Some of the feral trees in Michigan also yielded only sensitive isolates, but others yielded a high proportion of resistant isolates. In contrast to the Ohio sites, the Michigan sites may have included sites where DMIs had been used in the past or were located in communities with active orchards. The results in feral trees of Michigan were more closely aligned with the results found in the commercial orchards. Further population studies, including isolates from tart and sweet cherry trees in Michigan located away from commercial orchards, are needed to determine whether there is a basic difference in the baseline distribution of DMI sensitivity in populations of $B$. jaapii in Michigan versus Ohio, or if the observed difference is due to the movement of resistance from the orchards to surrounding areas.

The classic bioassay for detecting DMI resistance in $B$. jaapii and other fungi requires single-spore isolation of the fungus and subsequent plating on a culture medium amended with DMI fungicides at a range of concentrations. Although MMEA currently is the best medium for culturing this fungus that we have tested, $B$. jaapii grows to only $\approx 1 \mathrm{~cm}$ in diameter after 1 month of incubation and the entire process takes months to complete. Thus, the current bioassay method for the determination of $B$. jaapii sensitivity to DMIs is too slow to provide timely recommendations to growers. In this study, we developed a pair of PCR primers specific to $\mathrm{DMI}^{\mathrm{R}}$ isolates of $B$. jaapii. Using this pair of PCR primers, we could identify $\mathrm{DMI}^{\mathrm{R}} B$. jaapii isolates from pure fungal cultures within a few hours. With these primers, we also were able to detect $\mathrm{DMI}^{\mathrm{R}}$ B. jaapii from naturally infected leaves without the requirement of time-consuming culturing stages. Our primers, like those used for the PCR-based detection of $\mathrm{DMI}^{\mathrm{R}}$ strains of Penicillium digitatum (9), are based on species-specific sequences upstream of the CYP51 gene that are implicated in overexpression of this gene (10). We believe that this PCR method is robust for detection of $\mathrm{DMI}^{\mathrm{R}}$ isolates of $B$. jaapii because all isolates tested to date contain the upstream sequences targeted in our PCR (Fig. 4B). The PCR method does not, however, distinguish between the different levels of DMI resistance. In all of the orchards tested, where DMIs use was known, resistant isolates made up $99.7 \%$ of the population. In all regions except Southwest, the number of isolates rated as resistant was higher than for the experimental orchard where practical resistance was observed. At this time, PCR-based detection would not distinguish between the populations found in southwest MI and the rest of the state. We do not yet know if the population frequencies observed in Southwest confer practical resistance. The PCR method may be overly sensitive as a confirmation of field resistance; however, the detection of $\mathrm{DMI}^{\mathrm{R}}$ isolates in an orchard would serve as a warning sign that practical resistance may be imminent or present.

The fitness of $\mathrm{DMI}^{\mathrm{R}}$ isolates of $B$. jaapii has not been investigated. Overexpression of CYP51 has been reported as a mechanism for conferring reduced sensitivity to DMIs in other fungi $(10,25)$. We recently determined that the overexpression of CYP51 conferred DMI resistance in B. jaapii and that this phenotype was strongly correlated with the presence of a truncated transposable element upstream of CYP51 (21). This result raises the possibility that the overexpression of CYP51 in $\mathrm{DMI}^{\mathrm{R}}$ isolates may impose deleterious effects on the fitness of the $\mathrm{DMI}^{\mathrm{R}}$ isolates in orchards without DMI selection pressure. Thus, the frequency of resistant isolates in the pathogen population may decline after growers cease using DMIs or use them in combination or alternation with other fungicides. Our investigations of alternatives to DMI fungicides for CLS control have centered on strobilurins and copper compounds. Copper was an effective and widely used CLS fungicide in the 1930s (14); since then, the use of copper has significantly diminished because of phytotoxicity concerns and the ease of use of modern synthetic fungicides. Our experiments with spray timings and additives such as hydrated lime have shown that copper compounds can be used effectively as CLS fungicides on tart cherry with only minor phytotoxicity problems. It is clear that existing and emerging fungicide resistance problems with DMIs and strobilurins, combined with the decreasing availability of new fungicide chemistries, signifies an ongoing need to investigate novel disease control strategies and to reevaluate all available disease control alternatives.

TABLE 3. Detection of demethylation inhibitor fungicide-resistant $\left(\mathrm{DMI}^{\mathrm{R}}\right)$ isolates of Blumeriella jaapii using a polymerase chain reaction (PCR) method ${ }^{\mathrm{a}}$

\begin{tabular}{|c|c|c|c|c|c|}
\hline \multirow[b]{2}{*}{ Source of isolates ${ }^{b}$} & \multirow[b]{2}{*}{ Host plant ${ }^{\mathrm{c}}$} & \multirow[b]{2}{*}{ Number of isolates } & \multirow[b]{2}{*}{ Sensitivity to fenbuconazole ${ }^{d}$} & \multicolumn{2}{|c|}{ PCR detection of resistance ${ }^{\mathrm{e}}$} \\
\hline & & & & $434 \mathrm{bp}$ & $344 \mathrm{bp}$ \\
\hline \multirow[t]{2}{*}{ Ohio } & SC & 11 & $\mathrm{~S}$ & 0 & 0 \\
\hline & $\mathrm{TC}$ & 8 & S & 0 & 0 \\
\hline & $\mathrm{BC}$ & 1 & $\mathrm{~S}$ & 0 & 0 \\
\hline & $\mathrm{MC}$ & 1 & $\mathrm{HM}$ & 1 & 0 \\
\hline & $\mathrm{TC}$ & 2 & LM & 2 & 0 \\
\hline & SC & 2 & $\mathrm{R}$ & 2 & 0 \\
\hline \multirow{2}{*}{ Southwest MI } & $\mathrm{TC}$ & 2 & LM & 2 & 0 \\
\hline & $\mathrm{TC}$ & 2 & $\mathrm{R}$ & 2 & 0 \\
\hline \multirow[t]{3}{*}{ Western MI } & TC & 3 & LM & 3 & 0 \\
\hline & $\mathrm{TC}$ & 3 & HM & 3 & 0 \\
\hline & $\mathrm{TC}$ & 4 & $\mathrm{R}$ & 4 & 0 \\
\hline Northwest MI & TC & 9 & LM & 9 & 0 \\
\hline
\end{tabular}

a All isolates tested positive as B. jaapii using the primer pair Bj-f and Bj-r.

${ }^{\mathrm{b}}$ Central MI, Ingham and Ionia counties; Eastern MI, Tuscola County; Southwest MI, van Buren County; Western MI, Oceana County; Northwest MI, Benzie, Grand Traverse, and Leelanau counties; Ohio, Columbiana, Mahoning, and Trumbull counties.

c Abbreviations: BC, black cherry; SC, sweet cherry; TC, tart cherry; MC, mahaleb cherry.

${ }^{\mathrm{d}}$ DMI-sensitivity phenotypes were based on the concentration of fenbuconazole $(\mu \mathrm{g} / \mathrm{ml}$ a.i. $)$ at which colony growth was inhibited. Sensitive $(\mathrm{S})=0.2$, low moderate $(\mathrm{LM})=3.0$, high moderate $(\mathrm{HM})=5.0$, and resistant $(\mathrm{R})=>0.5 \mu \mathrm{g} / \mathrm{ml}$ a.i.

e PCR detection was based on the amplification of fragments upstream of B. jaapii CYP51 that were correlated with resistance. The primer pair DMI$\mathrm{R}-\mathrm{Bj}-\mathrm{F}$ and DMI-R-Bj-R was used, and either of two fragment sizes were detected. The number of strains with positive amplification of either fragment size is shown. 


\section{ACKNOWLEDGMENTS}

This work was supported by the United States Department of Agriculture CSREES Risk Avoidance and Mitigation grant program (200351101-02120), the Michigan Cherry Committee, and the Agricultural Experiment Stations of Michigan and Wisconsin. We thank B. Klein and M. Anderson for technical assistance in the field trials; B. Shane and M. Danilovic for assistance in locating commercial orchard sites; two anonymous reviewers for their thoughtful reviews and helpful comments; and the Marco Polo Project, Alma UE, University of Bologna for fellowship support for R. Berardi for a 6-month research internship at Michigan State University.

\section{LITERATURE CITED}

1. Asai, K., Tsuchimori, K., Okonogi, K., Perfect, J. R., Gotoh, O., and Yoshida, Y. 1999. Formation of azole-resistant Candida albicans by mutation of sterol 14-demethylase P450. Antimicrob. Agents Chemother. 14:1163-1169.

2. Brent, K. J. 1995. Fungicide resistance in crop pathogens, How can it be managed. FRAC Monograph No. 1, Global Crop Protection Federation, Brussels.

3. Delye, C., Bousset, L., and Corio-Costet, M. F. 1998. PCR cloning and detection of point mutations in the eburicol $14 \alpha$-demethylase (CYP51) gene from Erysiphe graminis f. sp. hordei, a "recalcitrant" fungus. Curr. Genet. 34:399-403.

4. Delye, C., Laigret, F., and Corio-Costet, M. F. 1997. A mutation in the $14 \alpha$-demethylase gene of Uncinula necator that correlates with resistance to a sterol biosynthesis inhibitor. Appl. Environ. Microbiol. 63:2966-2970.

5. Erickson, E. O., and Wilcox, W. F. 1997. Distributions of sensitivities to three sterol demethylation inhibitor fungicides among populations of Uncinula necator sensitive and resistant to triadimefon. Phytopathology 87:784-791.

6. Franz, R., Kelly, S. L., Lamb, D. C., Kelly, D. E., Ruhnke, M., and Morschhauser, J. 1998. Multiple molecular mechanisms contribute to a stepwise development of fluconazole resistance in clinical Candida albicans strains. Antimicrob. Agents Chemother. 42:3065-3072.

7. Golembiewski, R. C., Vargas, J. M., Jones, A. L., and Detweiler, A. R. 1995. Detection of demethylation inhibitor (DMI) resistance in Sclerotinia homoeocarpa populations. Plant Dis. 79:491-493.

8. Gubler, W. D., and Ypema, H. L. 1996. Occurrence of resistance in Uncinula necator to triadimefon, myclobutanil, and fenarimol in California grapevines. Plant Dis. 80:902-909.

9. Hamamoto, H., Haseqawa, K., Nakaune, R., Lee, Y. J., Akutsa, K., and Hibi, T. 2001. PCR-based detection of sterol demethylation inhibitorresistant strains of Penicillium digitatum. Pest Manage. Sci. 57:839-883.

10. Hamamoto, H., Haseqawa, K., Nakaune, R., Lee, Y. J., Makizumi, Y., Akutsu, K., and Hibi, T. 2000. Tandem repeat of a transcriptional en-

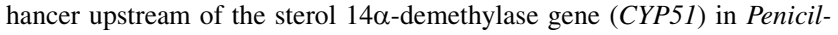
lium digitatum. Appl. Environ. Microbiol. 66:3421-3426.

11. Hayashi, K., Schoonbeck, H., and De Waard, M. A. 2002. Expression of the $\mathrm{ABC}$ transporter BcatrD from Botrytis cinerea reduces sensitivity to sterol demethylation inhibitor fungicides. Pestic. Biochem. Physiol. 73:110-121.

12. Jones, A. L., Ehret, G. R., Sundin, G. W., Nugent, J. E., and Klein, W. M. 2003. New fungicide evaluation on Montmorency tart cherries for leaf spot control, 2002. Fungic. Nematicide Tests 58:STF003.

13. Karaoglanidis, G. S., Ioannidis, P. M., and Thanassoulopoulos, C. C.
2000. Reduced sensitivity of Cercospora beticola isolates to steroldemethylation-inhibiting fungicides. Plant Pathol. 49:567-572.

14. Keitt, G. W. 1937. The epidemiology and control of cherry leaf spot. Wisc. Agric. Exp. Stn. Res. Bull. 132.

15. Kendall, S. J., Hollomon, D. W., Cooker, L. R., and Jones, D. R. 1993. Changes in sensitivity to DMI fungicides in Rhynchosporium secalis. Crop Prot. 12:357-362.

16. Köller, W. 1991. Fungicide resistance in plant pathogens. Pages 679-720 in: CRC Handbook of Pest Management in Agriculture. 2nd ed., Vol. 2. D. Pimental and A. A. Hanson, eds. CRC Press, Boca Raton, FL.

17. Köller, W., and Wilcox, W. F. 1999. Evaluation of tactics for managing resistance of Venturia inaequalis to sterol demethylation inhibitors. Plant Dis. 83:857-863.

18. Köller, W., Wilcox, W. F., Barnard, J., Jones, A. L., and Braun, P. G. 1997. Detection and quantification of resistance of Venturia inaequalis populations to sterol demethylation inhibitors. Phytopathology 87:184-190.

19. Ma, Z., and Michailides, T. J. 2005. Advances in understanding molecular mechanisms of fungicide resistance and molecular detection of resistant genotypes in phytopathogenic fungi. Crop Prot. 24:853-863.

20. Ma, Z., Morgan, D., Felts, D., and Michailides, T. J. 2002. Sensitivity of Botryosphaeria dothidea from California pistatachio to tebuconazole. Crop Prot. 21:829-835.

21. Ma, Z., Proffer, T. J., Jacobs, J. L., and Sundin, G. W. 2006. Overexpression of the $14 \alpha$-demethylase (CYP51) target gene mediates fungicide resistance in Blumeriella jaapii. Appl. Environ. Microbiol. 72:2581-2585.

22. McGrath, M. T. 2001. Fungicide resistance in cucurbit powdery mildew, experiences and challenges. Plant Dis. 85:236-245.

23. McGrath, M. T., and Shishkoff, N. 2001. Resistance to triadimefon and benomyl, dynamics and impact on managing cucurbit powdery mildew. Plant Dis. 85:147-154.

24. Reynolds, K. L., Brenneman, T. B., and Bertrand, P. F. 1997. Sensitivity of Cladosporium caryigenum to propiconazole and fenbuconazole. Plant Dis. 81:163-166.

25. Romero, R. A., and Sutton, T. B. 1997. Sensitivity of Mycosphaerella fijiensis, causal agent of black Sigatoka of banana, to propiconazole. Phytopathology 87:96-100.

26. Schnabel, G., and Jones, A. L. 2001. The 14 $\alpha$-demethylase (CYP51A1) gene is overexpressed in Venturia inaequalis strains resistant to myclobutanil. Phytopathology 91:102-110.

27. Smith, V. F., Parker, D. M., and Köller, W. 1991. Sensitivity distribution of Venturia inaequalis to the sterol demethylation inhibitor flusilizole, baseline sensitivity and implications for resistance monitoring. Phytopathology 81:392-396.

28. Stanis, V. F., and Jones, A. L. 1985. Reduced sensitivity to sterol inhibiting fungicide in field isolates of Venturia inaequalis. Phytopathology 75:1098-1101.

29. Sundin, G. W., Ehret, G. R., McManus, P. S., Nugent, J. E., Klein, W. M., Anderson, M. D., and Proffer, T. J. 2005. Evaluation of new fungicide rotations for cherry leaf spot control on Montmorency tart cherries in NW Michigan, 2004. Fungic. Nematicide Tests 60:STF004.

30. Wharton, P. S., Iezzoni, A., and Jones, A. L. 2003. Screening cherry germ plasm for resistance to leaf spot. Plant Dis. 87:471-477.

31. Zehr, E. I., Luszcz, L. A., Olien, W. C., Newal, W. C., and Toler, J. E. 1999. Reduced sensitivity in Monilinia fructicola to propiconazole following prolonged exposure in peach orchards. Plant Dis. 83:913-916.

32. Zwiers, L. H., Sterigopoulos, I., Van Nistelrooy, J. G. M., and De Waard, M. A. 2002. ABC transporters and azole susceptibility on laboratory strains of the wheat pathogen Mycosphaerella graminicola. Antimicrob. Agents Chemother. 46:3900-3906. 